\title{
AVALIAÇÃO DA QUALIDADE DE SERVIÇOS EM CENTROS DE FITNESS NO RIO DE JANEIRO: PROPOSTA DE INSTRUMENTO ESPECÍFICO PARA INSTRUTORES
}

\author{
${ }^{1}$ Edvaldo de Farias \\ ${ }^{2}$ Luis Felgueiras e Sousa Quaresma \\ ${ }^{3}$ José Manuel Vilaça-Alves
}

\section{Resumo}

Objetivo do estudo: Buscou-se com a pesquisa construir um instrumento para avaliar qualidade dos serviços prestados em centros de fitness no Rio de Janeiro considerando a perspectiva dos instrutores que neles atuam.

Metodologia/abordagem: $\mathrm{O}$ método utilizado foi uma pesquisa de campo, com aplicação de um instrumento adaptado e específico, em 216 centros de fitness e 164 profissionais na cidade do Rio de Janeiro - RJ, Brasil, com tratamento dos resultados pela análise fatorial exploratória, com vista a obter um instrumento com um número menor de dimensões e itens.

Originalidade/Relevância: A pesquisa é importante porque propõe um instrumento construído sob a perspectiva de instrutores de academia, uma vez que os estudos existentes apresentam instrumentos desenvolvidos exclusivamente sob a ótica dos consumidores de serviços.

Principais resultados: Os resultados sugerem que os instrutores são adultos-jovens, na maioria homens, graduados em Educação Física e atuando há 15 anos no máximo, desatualizados e sem buscar especialização nem interessados em pesquisas na área de atuação. A AFE permitiu a redução de 40 itens distribuídos por 4 dimensões do instrumento original, para 18 itens distribuídos por 5 dimensões, que explicam $61,70 \%$ da variância comum dos dados, reduzindo em $52,5 \%$ o número de itens.

Contribuições teóricas/metodológicas: apresenta-se um novo instrumento com estrutura fatorial boa e aceitável para a avaliação da qualidade de serviços nessas empresas de fitness, atestando que o modelo proposto possui validade fatorial e consistência interna adequadas, sendo indicado para utilização como instrumento de avaliação da qualidade dos serviços em centros de fitness no Rio de Janeiro na perspectiva dos instrutores.

Palavras-chave: Qualidade. Serviços. Academias. Instrutores. Instrumento.

\section{Como referenciar em APA:}

Farias, E., Quaresma, L., \& Vilaça-Alves, J. (2019). Avaliação da Qualidade de Serviços em Centros de Fitness no Rio de Janeiro: Proposta de Instrumento Específico para Instrutores. PODIUM Sport, Leisure And Tourism Review, 8(2), 151-173. https://doi.org/10.5585/podium.v8i2.312

\footnotetext{
${ }^{1}$ Universidade Estácio de Sá - UNESA, Rio de Janeiro, (Brasil). E-mail: edvaldo.farias@gmail.com Orcid: https://orcid.org/0000-0002-9660-4014

${ }^{2}$ Universidade de Trás-os-Montes e Alto Douro - UTAD, (Portugal). E-mail: luisquar@utad.pt Orcid: https://orcid.org/0000-0002-0943-4011

${ }^{3}$ Universidade de Trás-os-Montes e Alto Douro - UTAD, (Portugal). E-mail: josevilaca@utad.pt Orcid: https://orcid.org/0000-0001-5399-7797
} 


\title{
EVALUATION OF THE QUALITY OF SERVICES IN FITNESS CENTERS IN RIO DE JANEIRO: PROPOSAL FOR A SPECIFIC INSTRUMENT FOR INSTRUCTORS
}

\begin{abstract}
Objective: The research aimed to build an instrument to evaluate the quality of services provided in fitness centers in Rio de Janeiro considering the perspective of the instructors who work in them.

Methodology / Approach: The method used was application of an adapted and specific instrument, in 216 fitness centers and 164 professionals in the city of Rio de Janeiro - RJ, Brazil, with treatment of the results by exploratory factor analysis, in order to obtain an instrument with a smaller number of dimensions and items.
\end{abstract}

Originality / Relevance: Propose an instrument built from the perspective of fitness center instructors, as existing studies present instruments designed exclusively from the perspective of clients.

Main results: The results describe that the instructors are young adults, mostly men, graduated in Physical Education and working for a maximum of 15 years, outdated and without seeking specialization or interested in research in the field. EFA allowed the reduction of 40 items distributed over 4 dimensions of the original instrument to 18 items distributed over 5 dimensions, which explain $61.70 \%$ of the common variance of the data, reducing the number of items by $52.5 \%$.

Theoretical / methodological contributions: We present a new instrument with a good and acceptable factor structure for the evaluation of the quality of services in these fitness companies, attesting that the proposed model has adequate factor validity and internal consistency, being indicated for use as an instrument for evaluating the quality of services in fitness centers in Rio de Janeiro from the instructors perspective.

Keywords: Quality. Services. Instrument. Fitness centers. Instructors. 


\section{EVALUACIÓN DE LA CALIDAD DE LOS SERVICIOS EN CENTROS DE FITNESS EN EL RÍO DE JANEIRO: PROPUESTA DE INSTRUMENTO ESPECÍFICO PARA LOS INSTRUCTORES}

\section{Resumen}

Objetivo: El objetivo de la investigación fue construir un instrumento para evaluar la calidad de los servicios en la visión de los instructores.

Método: Se realizó una investigación de campo, con la aplicación de un instrumento adaptado y específico, en 216 centros de acondicionamiento físico y 164 profesionales en la ciudad de Río de Janeiro - RJ, Brasil, con tratamiento de los resultados mediante análisis factorial exploratorio, para obtener un instrumento. con un menor número de dimensiones y artículos.

Originalidad / Relevancia: La investigación es importante porque propone un cuestionario construido desde la perspectiva de los instructores de la academia, ya que los estudios existentes presentan instrumentos desarrollados exclusivamente desde la perspectiva de los consumidores de servicios.

Resultados: Los resultados muestran que los instructores son adultos jóvenes, en su mayoría hombres, graduados en Educación Física y trabajando por un máximo de 15 años, obsoletos y sin buscar especialización o interesados en la investigación en el campo. AFE permitió la reducción de 40 ítems distribuidos en 4 dimensiones del instrumento original, a 18 ítems distribuidos en 5 dimensiones, lo que explica el $61.70 \%$ de la varianza de datos comunes, reduciendo el número de ítems en un 52.5\%.

Contribuciones teóricas / metodológicas: La investigación presenta un cuestionario con una estructura de factores buena y aceptable para la evaluación de la calidad de los servicios en estas empresas de acondicionamiento físico, lo que demuestra que el modelo propuesto tiene una validez de factor y una consistencia interna adecuadas, indicando su uso como un instrumento para evaluar la calidad de los servicios en Gimnasios en Río de Janeiro desde la perspectiva de los instructores.

Palabras clave: Calidad. Servicios. Cuestionario. Centros de fitness. Instructores. 


\section{Introdução}

Muitas são as diferenças entre a sociedade pósindustrial e os modelos produtivos anteriores a ela, mas, a transferência do "peso" da produção de bens tangíveis para os serviços é o que define o cenário econômico global, transformando o mercado de serviços em um fator essencial, tanto para a as economias dos países quanto para a ocupação da mãode-obra, já que a produção de bens manufaturados, sem os serviços adjacentes, gera trajetórias curtas na circulação de capital (Fitzsimmons \& Fitzsimmons, 2000).

No Brasil, os serviços desempenham papel semelhante, participando de modo crescente no PIB, indo de $60 \%$ entre 1996 e 1999 a 69,4\% em 2014, quando havia 1.332.260 empresas na atividade de prestação de serviços, ocupando 13.042.000 de pessoas (IBGE, 2014). Nesse mesmo contexto, serviços relacionados especificamente as práticas de lazer, saúde e entretenimento familiar, apresentaram 415.176 empresas $(31,2 \%)$, ocupando o $2^{\circ}$ lugar em ocupação de mão-de-obra, com aproximadamente 3 milhões de pessoas, equivalendo a $22,3 \%$ de toda a força de trabalho ativa do país (IBGE, 2017).

Especificamente no mercado dos serviços em fitness, é evidente um aumento na sua oferta, e no Brasil, a IHRSA - International Health Racquet Sports Association, relata um crescimento de $10 \%$ ao ano, fazendo com que o Brasil saísse de 14 mil academias em 2009 para aproximadamente $32 \mathrm{mil}$ unidades em pleno funcionamento em 2016, equivalendo a um crescimento de $127 \%$, contra a média mundial de $50 \%$ no mesmo período. Estes números posicionam o Brasil como o $2^{\circ}$ mercado mundial, atrás apenas dos EUA (IHRSA, 2016).

Nesse viés, Batista, Joaquim \& Carvalho (2016) afirmam que o Brasil tem potencialidade para tornarse liderança mundial em fitness nos próximos anos, devido pujança da economia nacional, o crescente interesse pelas práticas em fitness nos diferentes estratos sociais, e o aumento do poder de compra da população, potencializado ainda mais pelas ofertas low cost/low price.

Registre-se que a nomenclatura "empresas fitness" aqui adotada, representa uma ampliação do conceito genérico de academias de ginástica, em função da existência, na cidade do Rio de Janeiro, de centros destinados a prática de exercícios físicos orientados cujas ofertas de serviços nem sempre são de modalidades coletivas de ginástica, tais como os estúdios de treinamento personalizado, funcional e assemelhados, cujas ofertas atendem as mesmas demandas, mas sob forma de modalidades específicas.

Assim, mesmo diante da evidente prosperidade do segmento de negócios em fitness na cidade do Rio de Janeiro, não é comum nessas empresas a adoção de estratégias e ferramentas voltadas a mensurar qualidade dos serviços prestados a clientes, o que torna relevante e necessária a existência de instrumentos construídos a partir das percepções tanto dos consumidores com dos gestores e dos profissionais que operam a entrega direta de serviços, quais sejam os profissionais de Educação Física que atuam na prescrição e orientação de exercícios, aqui denominados instrutores.

Associado a isso, é sabido que qualidade constitui um conceito abstrato e, portanto, difícil de definir e mensurar, e por isso mesmo, vários autores são unânimes ao afirmar que a qualidade de serviços e a sua avaliação têm dimensões múltiplas e interdependentes, tanto pela intangibilidade do seu produto final, quanto pelas interações entre colaboradores, gestores e beneficiários envolvidos (Ko \& Pastore, 2005; Quaresma, 2008; Chelladurai, 2014).

Essa interação fica evidente nas propostas de 2 instrumentos apresentadas por Farias, Quaresma, Vilaça-Alves \& Neves (2018) e Farias, Quaresma, Neves \& Vilaça-Alves (2018), que destacam a relevância de considerar todas essas dimensões na mensuração da qualidade dos serviços prestados por empresas fitness, sob a ótica dos clientes e dos gestores respectivamente.

Estudos mais recentes, como Howat \& Assaker (2013, 2016); Avourdiadou \& Theodorakis (2014); Najafzadeh \& Shiri (2015); Yoshida (2017) têm sido desenvolvidos com foco na adaptação, criação ou aplicação de instrumentos capazes de mensurar a satisfação dos clientes em relação a qualidade dos serviços e a experiência de consumo nas empresas fitness. Um traço comum em todos os instrumentos adotados nessas investigações é, exatamente, o fato de adotarem exclusivamente o uso da perspectiva do consumidor como única fonte para definir os indicadores adotados nessas avaliações.

Porém, se não há dúvidas quanto à necessidade dessa avaliação levar em conta a perspectiva dos clientes, é igualmente importante considerar que outros fatores devem estar alinhados à satisfação deles no momento exato da entrega, ao que Carlzon (2005) denominava "hora da verdade". Esse momento, segundo o autor, é resultante do contato direto entre o 
cliente e os colaboradores (instrutores) da empresa, quando então ele constrói sua imagem e impressões sobre os serviços a partir da experiência vivida no momento do consumo. Em síntese, na prestação de serviços, como afirmam Kotler \& Armstrong (2015), quem os presta faz parte dele.

Diante desse contexto, a pesquisa em tela teve como objetivo, propor a construção de um instrumento específico, capaz de mensurar a qualidade dos serviços prestados por estes centros de fitness, considerando a perspectiva dos profissionais (instrutores) que nela atuam e respondem diretamente pela entrega desses serviços, posto que são os responsáveis pela geração da percepção objetiva dos clientes sobre o que consomem nesses centros.

\section{Revisão da Literatura}

\section{Os Instrutores na Prestação de Serviços em Centros de Fitness}

No que diz respeito a gestão de negócios no esporte, no que tange a prestação de serviços, Chelladurai (2014) propõe que eles podem ser classificados da seguinte forma: i) serviços orientados a participantes, ao qual academias ou centros de fitness pertencem; ii) serviços orientados a espectadores; iii) serviços de patrocínio; e iv) serviços de doação e ideias sociais. Dentre esses, os serviços orientados a participantes são exatamente aqueles nos quais clientes se envolvem fisicamente em algum tipo de esporte ou atividade física orientada, em espaços físicos específicos, utilizandose de recursos materiais inerentes as modalidades escolhidas. Neles, recebem instrução, orientação ou coaching, realizados por profissionais especialistas, aqui denominados instrutores.

Estes profissionais, componentes da estrutura de academias, estúdios, centros de treinamento físico e espaços congêneres, voltados a estética, saúde, bemestar ou aptidão física, são responsáveis diretamente pela entrega objetiva desses serviços aos clientes e, por conseguinte, pela qualidade desses serviços.

Chelladurai (2014) destaca ainda que a capacitação e especialização, atreladas a capacidade de planejamento e liderança, são competências decisivas na avaliação dos serviços pelos clientes, ou consumidores.

Para isso, considera fundamental que esses profissionais sejam capazes também de exercer uma autoavaliação dos serviços prestados por eles, além de desenvolverem uma visão ampla em relação a essa qualidade e em que medida ela está alinhada as expectativas e interesses de seus clientes.

Assim, é possível afirmar que a performance de uma organização pode ser traduzida como a relação entre o valor criado pela utilização dos bens produzidos e o valor que os proprietários desses mesmos bens esperam obter e, por isso mesmo, é possível inferir que sua performance no mercado onde atua é produzida coletivamente, ou seja, pela tríade envolvida no processo de produção formada por gestores, colaboradores e clientes (Ortner, 2000; Garbi, 2002; Mariano, 2017).

Corroborando a importância dos colaboradores nas empresas, sob a ótica da qualidade de serviços prestados encontramos unanimidade entre Macedo, Rodrigues, Johann, \& Cunha (2003), Chiavenato (2014), Rego (2015) quando afirmam a necessidade de sinergia entre as empresas e seus recursos humanos (aqui denominados instrutores), posto que as melhorias devem acontecer a partir delas, criando as condições para que processos e resultados sejam progressivamente melhores. Assim, podemos afirmar que organizações fazem sentido se, e somente se, forem consideradas como equipes de pessoas agindo e interagindo com objetivos comuns. Em outras palavras, produzir bens ou serviços, atender clientes e prosperar somente é possível se houver sintonia entre todos os partícipes dessas três fases.

Além disso, os mesmos autores convergem para o entendimento de que os recursos humanos são fator primordial para que negócios existam e prosperem numa relação simbiótica positiva e produtiva e, por esse motivo, tratar da qualidade dos serviços prestados por essas empresas não pode prescindir da percepção e entendimento do que estes mesmos colaboradores têm em relação ao conjunto de indicadores destinados a avaliar a qualidade dos serviços que prestam.

Dessa forma, a implantação de políticas de gestão da qualidade cria facilidades e, portanto, possibilita resultados exitosos, exigindo que modernas práticas de gestão de pessoas ocorram tanto na organização do trabalho em si quanto nas relações entre colaboradores.

Com isso, a gestão da qualidade desses serviços deve passar obrigatória e prioritariamente pelas pessoas e seus talentos, conhecimentos, habilidades e atitudes, ingredientes de serviços de qualidade, como afirmava Bilhim (2006) ao discutir a necessidade de uma gestão estratégica dos recursos humanos nas organizações. 


\section{A Qualidade de Serviços e sua Avaliação em Centros de Fitness}

No que diz respeito aos espaços voltados à oferta orientada de exercícios físicos, aqui tratados por centros de fitness, sabe-se que seu surgimento no mercado brasileiro resultou da necessidade de pessoas que tinham interesse por essa prática, mas queriam fazê-la fora dos clubes.

Este segmento, orientado à oferta de serviços voltados ao bem estar, que Saba (2006) denominou indústria do fitnes, foi considerado por ele como um dos mais promissores em termos econômicos, sabendo-se que entre eles estão também produtos, como vitaminas, alimentos dietéticos, tratamentos cosméticos, medicina preventiva e outras opções que, direta ou indiretamente, se relacionam à prática de exercícios físicos.

Nesse contexto, e com propósito de ofertar serviços nessa área, abriu-se espaço para o surgimento de novos players, criando um ambiente mercadologicamente competitivo (Tibola, Silva, Vieira \& Tontini, 2011; Farias, Quaresma, VilaçaAlves \& Neves, 2018), no qual surgiram centros especializados na oferta de serviços de avaliação, prescrição e orientação da prática de exercícios físicos, em diferentes modalidades, compostos por corpo técnico adequado e capacitado para atender as demandas dos seus beneficiários. Tudo isso, obviamente, deveria ser acompanhado por níveis elevados de satisfação desses consumidores, atraindo ainda clientes potenciais e tornando-os mercadologicamente competitivos (Saba, 2006; Dias, 2006; Linhares \& Freitas, 2011).

Sob essa ótica, diversos autores (Grönroos, 2007; Ladhari, 2009; Barreto, Santos, Gomes, Silva \& Menezes, 2012) descreveram a qualidade dos serviços como o maior fator de retenção de clientes, além de forte atrativo para clientes potenciais, trazidos por quem já conhece e experimenta uma qualidade diferenciada nos serviços que consome. Com isso, são reduzidos os gastos com captação de novos clientes, posto que seu convencimento passa a ser feito por seus clientes regulares, denominados de "apóstolos" por Lovelock \& Wright (2003).

Assim, é evidente a necessidade das empresas de serviços investirem progressivamente mais na gestão da qualidade de suas entregas à sociedade, visto que a crescente onda concorrencial demanda a manutenção de níveis elevados na satisfação de seus beneficiários, viabilizando assim a perenidade e prosperidade dos negócios (Barreto, Santos, Gomes, Silva \& Menezes, 2012; Farias, 2015, 2016).
Tal investimento demanda a criação de estratégias e instrumentos adequados à mensuração dessa satisfação em relação aos serviços que lhes são entregues, sob a ótica da adequação ao uso, ou seja, do quanto os serviços vão, efetivamente, ao encontro das suas expectativas. Esta criação deve permitir e garantir a eles, consumidores, que a qualidade dos serviços tem um sistema de gestão que lhes confere confiabilidade e perenidade (Lovelock \& Wright, 2003; Grönroos, 2007; Quaresma, 2008; Sayers, 2012, Farias, 2015, 2016; Farias, Quaresma, VilaçaAlves, Neves, 2018).

Diante desse contexto, Pinheiro \& Pinheiro (2006); Campos (2007); Quaresma (2008); Yildiz ( 2011); Pereira Filho, Campos \& Dantas (2013) destacam, de modo uníssono, a relevância na gestão dos centros de fitness, assim como nas demais empresas de serviços, de não somente captar clientes e oferecer-lhes o básico. É preciso também conhecer comportamentos, necessidades, interesses e desejos para promover o encantamento desses clientes a partir das ações dos instrutores, responsáveis diretos pela entrega final dos serviços naquilo que Carlzon (2005), denominou de "hora da verdade", da relação de consumo.

Agindo assim, criam-se condições para que se vá além de características e atributos genéricos, com nos apresentou o instrumento SERVQUAL proposto por Berry, Parasuraman, \& Zeithaml (1988), cuja finalidade era mensurar do nível de qualidade dos serviços sob a ótica de seus beneficiários em relação a indicadores ou atributos, sobre os quais esses clientes são levados a avaliar uma situação ideal de empresa prestadora do serviços para, em seguida, avaliar o desempenho real desta empresa em face dos mesmos indicadores de desempenho.

Mesmo reconhecendo a contribuição desse modelo, as limitações que o caracterizam tornam insuficiente a sua adoção por centros de fitness, na medida em que apresenta variáveis genérico em relação aos serviços, subtraindo a possibilidade de uma avaliação de indicadores específicos dos serviços nesse segmento de negócios.

Além disso, e pelo fato de ser baseado na Teoria dos "Gaps", o SERVQUAL conduz à avaliação polarizada dos resultados, na medida em que ambas as dimensões (ideal e real) são feitas apenas após a prestação dos serviços quando, na verdade, deveria colher as expectativas dos clientes antes do consumo seguidas da avaliação objetiva da experiência após o consumo dos serviços entregues (Pereira Filho, Campos, \& Dantas, 2013). 
O traço comum das investigações sobre indicadores para a mensuração da qualidade de serviços em centros de fitness é a inquestionável importância dessa medição como estratégia de gestão e subsídio as tomadas de decisão por seus gestores. Portanto, essas decisões, pela sua capacidade de orientar o desenvolvimento e a gestão dos negócios, precisam ser subsidiadas por diagnósticos precisos sobre a qualidade percebida pelos stakeholders envolvidos na produção daquilo que entregam a sociedade. Com isso, é plenamente possível gerar ações de retenção e fidelização, tornar-se competitivo e, por conseguinte, ampliar o ciclo de vida desses beneficiários na relação de consumo dos serviços que lhes são entregues (Morgan \& Rego, 2006). Podemos afirmar, portanto, que talvez essa seja a maior contribuição que a mensuração da qualidade dos serviços pode oferecer aos gestores, qual seja, instrumentalizá-lo para uma gestão eficaz.

Em relação ao enquadramento das empresas fitness, quanto ao processo de prestação de serviços, encontramos em Silvestro, Fitzgerald, Johnston, \& Voss (1992) uma interessante classificação ao sugerirem a existência de três tipos distintos: (i) serviços de grande consumo (mass services), (ii) service shop e, (iii) serviços profissionais (professional services), cada um deles com suas respectivas caracterizações.

Nessa classificação, o tipo (iii) ou serviços profissionais (professional services), explica exatamente os serviços em fitness ou desportivos, exatamente por apresentar alto grau de envolvimento e poder de decisão do front office (instrutores), elevado nível de personalização das entregas com foco nas pessoas, nos processos e dedicando elevada atenção as necessidades dos clientes, assumindo assim a possibilidade de personalização das entregas. Com isso, o cliente torna-se parte essencial do serviço, já que a interação com ele é fator primordial, demandando ao mesmo tempo, foco na produção, nas entregas e ainda nas inovações e tendências, buscando níveis elevados de satisfação e fidelização (Linhares \& Freitas, 2011).

Sobre isso, Osti (2009) já afirmava que, pela semelhança de ofertas dos centros de fitness, com equipamentos e modalidades transformados em commodities, a atenção passava a voltar-se para a criação de "diferenciais" no atendimento, seja em termos de horários diversificados ou da oferta de novas modalidades. Assim, frente à crescente concorrência do setor e a multiplicidade de ofertas semelhantes, essas empresas passavam a deparar-se com altos níveis de rotatividade dos clientes, criando por força de consequência dificuldades de manter a retenção deles e, por conseguinte, uma receita estável e minimamente previsível.

Sobre essa dificuldade na retenção de clientes, Alexandris, Douka, Papadopoulos, \& Kaltsatou (2008) e Farias $(2015,2016)$ reconheceram ser este um dos maiores desafios dos gestores desses centros, pois além da redução nos gastos com captação de novos clientes, a lealdade oferece benefícios concorrentes. Clientes fiéis compram mais, predispõem-se a consumir mais serviços e ainda indicam estes serviços para pessoas de seus círculos de relacionamentos, agindo como fiéis defensores sem que cobrem absolutamente nada por isso.

Com isso, podemos afirmar que a satisfação de clientes é precursora da fidelização na medida em que, no segmento fitness, caracterizado pela alta competitividade, é fundamental satisfazer necessidades e desejos dos clientes em face do potencial risco da escolha de outra empresa para alcançar esses objetivos, como descreveram de modo uníssono Lovelock \& Wright (2003); Lovelock, Wirtz, \& Hemzo (2011) e Kotler \& Armstrong (2015), ao afirmar que elevados índices de insatisfação em relação as entregas de serviços são gênese de altos níveis de deserção, podendo chegar ao ponto da carteira de clientes ativos ficar menor em relação a de ex-clientes, reduzindo na mesma proporção o contingente de defensores e a viabilidade financeira do negócio.

Pereira Filho, Campos, \& Dantas (2013) reforçam tal posição afirmando que é essencial conhecer com precisão o que, de fato, são serviços de qualidade na perspectiva de seus consumidores quando os compram, de tal forma que o design das ações de manutenção e melhoria sejam empreendidas de modo contínuo. Em outras palavras, para que um negócio neste segmento seja sustentável sob o ponto de vista mercadológico é fundamental conhecer os atributos adotados pelos clientes, para avaliar a qualidade daquilo que lhe é entregue pelos centros de fitness que escolheram para cuidar de sua saúde, por meio da prática de exercícios físicos (Barreto, Santos, Gomes, Silva, \& Menezes, 2012).

Mas não podemos assumir que apenas a satisfação dos beneficiários seja condição suficiente para que os negócios fitness sejam prósperos e que a qualidade dos serviços entregues à sociedade esteja garantida. Sobre isso Ortner (2000) e Rego et al. (2015) são unânimes ao afirmar que a implantação de uma política de qualidade nos serviços de uma empresa não pode ser vista apenas como ferramenta a ser adotada de forma isolada. Pelo contrário, representa 
uma mudança no modus operandi, nos pressupostos e na própria fílosofia da organização, traduzindo assim uma mudança nos modelos mentais de seus atores, vale dizer, dos instrutores.

Motta \& Moraes (2017) afirmam que, paralelamente à expansão do mercado de serviços em fitness representado por academias e assemelhados, percebe-se o incremento da concorrência e da diferenciação daqueles que conseguem manter-se de forma sustentável nesse mercado. Segundo eles, em passado recente, era praticamente impossível uma empresa deste segmento encerrar as atividades, o que já não traduz mais a realidade, posto que uma fração bastante significativa deles não conseguem mais fazer frente aos novos players deste segmento, sendo conduzidos à saída do mercado pelo encerramento das atividades ou a venda para esses mesmo empreendedores individuais associados a investidores financeiros, que se dispõem a criar academias de grande porte com equipamentos e tecnologia de última geração.

Ambos acabam por constituir ameaças, sob o ponto de vista mercadológico, pois os serviços que oferecem ao mercado são, ou prometem ser, de excelente qualidade. Assim, e para fazer com que esta qualidade seja percebida como uma característica da empresa, ações de fidelização são empreendidas a todo momento de tal forma que o negócio se torne sustentável financeiramente (Corrêa \& Ferreira, 2009).

Um exemplo, pertinente e atual, deste momento do segmento fitness é citado por Motta \& Moraes (2017) quando apresentam os casos das redes Bodytech ${ }^{\circledR} \mathrm{e}$ Smart $\mathrm{Fit}^{\circledR}$ de academias. Segundo eles, são reconhecidas por elevar o nível de profissionalismo e da concorrência no setor a partir da implantação de novas práticas de gestão, infraestrutura e profissionalização de equipes. São empresas que buscam eficiência e rentabilidade, por meio da oferta de experiências diferenciadas a clientes, cujo modelo de gestão é definido por um corpo diretivo composton ão por profissionais do fitness, mas sim por empresários com experiência em investimentos em diferentes setores.

Tibola, Silva, Vieira, \& Tontini (2011) registram a escassez de estudos voltados à identificação de atributos de qualidade voltados especificamente para centros de fitness, o que significa dizer que as tomadas de decisão dos gestores nessas empresas podem estar afastadas da realidade de seus clientes, o que abre a possibilidade de insatisfações e, por conseguinte, evasões. Seguindo o mesmo raciocínio, Barreto, Santos, Gomes, Silva \& Menezes (2012) e Motta \&
Moraes (2017) afirmam que, mesmo sendo intangíveis os serviços, ações totalmente concretas precisam ser empreendidas pelos gestores, no sentido de agregar-lhes a qualidade necessária, o que demanda identificar atributos específicos, operacionalizáveis e mensuráveis.

Estes autores relatam a existência de investigações com propósito de avaliar a qualidade dos serviços em outros segmentos de negócio, nos quais buscou-se atributos cada vez mais precisos, para subsidiar tomadas de decisão assertivas por gestores. Porém, isso só se torna possível, a partir do conhecimento detalhado dos aspectos utilizados por esses mesmos clientes nas suas avaliações, em relação à qualidade dos serviços pelos quais pagaram.

Lovelock, Wirtz, \& Hemzo (2011); Lopes (2014), afirmam que a escolha da abordagem mais adequada a cada empresa, e a cada tipo de serviço, exige uma análise cuidadosa das necessidades e expectativas daquele que procura informações sobre os serviços que pretende comprar, ou seja, o consumidor. Considerando que após a compra o processo de avaliação passa a ser feito por ele, numa comparação entre aquilo que esperava e aquilo que, de fato, recebeu, torna-se relevante a existência de padrões mínimos que sejam perceptíveis e tangíveis para uma avaliação criteriosa.

Demonstrando que a preocupação com a qualidade dos serviços em centros de fitness não é recente, Chelladurai, Scott, \& Haywood-Farmer (1987) descreveram o desenvolvimento da escala SAFS Scale of Attributes of Fitness Services composta por 30 itens, cujo propósito era mensurar o quanto cada um dos seus indicadores influenciava na decisão de compra dos serviços em academias de ginástica no Canadá.

Outra investigação, desenvolvida em centros esportivos na Coréia, relata a aplicação do instrumento QUESC - Quality Excellence of Sports Centers, com o mesmo foco e em forma de escala, contendo 45 itens distribuídos em 2 questionários distintos, abordando as expectativas dos clientes em relação aos serviços e o nível de qualidade desses serviços, na percepção dos respondentes (Kim \& Kim, 1995).

Numa outra pesquisa, aplicada sob a forma de survey, voltada à identificação dos fatores de satisfação de clientes em um centro esportivo municipal na cidade de Barcelona - Espanha, Triado, Aparicio \& Rimbau (1999) desenvolveram um instrumento específico e composto por 13 indicadores, avaliando uma amostra composta por 698 clientes regulares em 15 centros esportivos. 
Como resultado, cinco dimensões emergiram da análise fatorial, a saber: (i) qualidade das instalações, (ii) qualidade dos instrutores, (iii) custo, (iv) comunicação e (v) a importância do ambiente social.

Porém, a partir do momento em que fica evidente a força deste segmento de negócio, é consistente a posição assumida por Farias (2015); Farias (2016); Farias, Quaresma, Neves \& Vilaça-Alves (2018) quando chamam à atenção os gestores de empresas fitness, sugerindo como estratégia a busca contínua pelo incremento da satisfação dos clientes de suas empresas, considerando que o "pano de fundo", desse gerenciamento será sempre o pleno atendimento e superação das necessidades/expectativas desses clientes, por meio das ações dos instrutores das empresas.

Sobre a dimensão pessoal dos serviços, numa pesquisa desenvolvida por Osti (2009), com foco orientado a identificação dos atributos dos serviços de academias de ginástica que apresentassem os maiores índices de (in)satisfação na percepção dos clientes, foram analisados os dados de 318 frequentadores de cinco academias situadas na cidade de Londrina/PR. $\mathrm{O}$ estudo revelou que os consumidores leais se satisfazem mais com os aspectos intangíveis e relativos à dimensão funcionários, evidenciando que são as pessoas que "fazem a diferença".

Corroborando esse estudo, Morgan \& Rego (2006); Kotler \& Armstrong (2015) afirmam que há três razões fundamentais que justificam a busca pela satisfação de clientes em centros de fitness e seu monitoramento, demonstrando que todas as ações nessa direção se tornam menos custosas quando comparadas com a perda deles e tentativas subsequentes de resgatá-los.

Primeiramente, o "custo elevado da captação de novos clientes", quando comparado ao de manter clientes regulares, já que a primeira fase de conquista deles já aconteceu e, portanto, é suficiente a manutenção do nível de satisfação e atendimento de suas expectativas em relação aos serviços que consome.

Em segundo lugar, a "demanda competitiva pela satisfação com os serviços que compra", na medida em que estão sempre expostos a propostas, ofertas e vantagens adicionais, tornando imperativa a prática da inovação como estratégia para retê-los onde já estão ambientados.

Por derradeiro, temos o "valor do ciclo de vida dos clientes" como característica desse relacionamento, ou seja, quanto maior seu tempo de relacionamento menores esforços serão necessários para atender suas demandas, posto que a intimidade do consumo é viabilizada pela sintonia entre quem presta e quem recebe os serviços nos centros de fitness, respectivamente, os instrutores e os clientes.

Toda essa progressão demonstra de forma evidente o papel desempenhado pelas pessoas, vale dizer, colaboradores ou instrutores, na identificação dos atributos por meio dos quais os clientes avaliam os serviços que consomem nos centros de fitness (Lovelock \& Wright, 2003; Kotler \& Keller, 2006; Kotler \& Armstrong, 2015).

Sobre a necessidade específica, de envolver diferentes stakeholders na gestão do negócio, Quaresma (2008), afirma, em sua investigação sobre qualidade de serviços em campos de Golfe em Portugal, que ao gerir um serviço ligado ao esporte as ações gerenciais devem ser entendidas como importante fator da prestação do serviço e, por isso mesmo, precisam de algo mais do que "ações de qualidade".

Precisam, segundo ele, criar uma "cultura da qualidade" nas pessoas, processos e estruturas, de tal forma que o impacto e a diferenciação pela qualidade sejam uma característica de sua atuação no dia-a-dia.

Corroborando este autor, Mariano (2017) afirma, ao propor a adaptação de uma escala para avaliar a qualidade dos serviços voltada originariamente para clientes, com vistas a aplicá-la também a instrutores e gestores, que a percepção dos diferentes atores envolvidos na prestação de serviços permite a compreensão daquilo que é, de fato, relevante na avaliação da qualidade das entregas, posto que são dimensões interdependentes, mas igualmente inerentes à relação de consumo estabelecida.

Em síntese, para estes autores, o cenário competitivo e ávido por diferenciação nos obriga a considerar o sucesso empresarial como resultado de uma tríade composta por instrutores, clientes e gestores, de tal forma que viabilizem, em suas ações, a adequação entre expectativas, percepções e resultados.

Com isso, consideramos essencial a construção de um instrumento a partir da ótica de quem efetivamente faz a entrega desses serviços aos clientes, os instrutores, por expressar indicadores relativos à qualidade dos serviços pelos quais são responsáveis diretos.

Agindo assim, entende-se que propiciamos eficácia na gestão dessas empresas, na medida em que fornecemos subsídios não somente para a identificação de forças e fragilidades, mas também para a consequente construção de planos de ação de melhorias contínuas por parte dos seus gestores. 


\section{Metodologia}

Em relação a classificação da pesquisa, foram consideradas 4 dimensões distintas para caracterizála: (i) tipo de abordagem; (ii) natureza; (iii) objetivos ou fins e; (iv) procedimentos (Gerhardt \& Silveira, 2009).

Quanto ao tipo de abordagem classifica-se como qualitativa, por seu foco predominante não ser a representatividade numérica e nem a ratificação de julgamentos a priori do pesquisador, mas sim, a investigação do comportamento de grupos sociais em relação a um ou mais fenômenos, no caso, instrutores atuantes em centros de fitness no Rio de Janeiro (Feire \& Almeida, 2008).

Quanto aos objetivos a pesquisa classifica-se segundo Gil (2010); Gerhardt \& Silveira (2009), como exploratória e descritiva, por buscar maior familiaridade com o problema tornando-o mais explícito e tangível, quando não foi abordado sob a ótica adotada na investigação proposta. Ao mesmo tempo, descreve fatos e fenômenos de uma determinada realidade, estabelecendo relações entre variáveis que representam a ocorrência de posicionamentos, por meio da aplicação de técnicas padronizadas, que neste caso foram questionários (Marconi \& Lakatos, 2009).

Quanto aos procedimentos a pesquisa classifica-se como de campo, do tipo survey, por buscar informações diretamente com um ou mais grupos de interesse a respeito dos dados que se deseja obter, com adoção de um ou mais questionários como instrumento, nos quais os respondentes não são identificáveis, mantendo, portanto, a garantia do sigilo (Gerhardt \& Silveira, 2009).

Sobre a escolha do instrumento adotado respaldamo-nos em Tuckman (2012) quando afirma que existem três formas de recolher dados em investigações de natureza qualitativa, sendo uma delas o inquérito escrito (questionário). Para esse autor, a interpretação dos resultados pode desempenhar tanto a função de verificar hipóteses, como também a função heurística, quando enriquece a pesquisa exploratória, aumentando a propensão à descoberta, quando não há hipóteses a confirmar.

Ao mesmo tempo, a pesquisa teve uma abordagem quantitativa por investigar um grupo amostral grande e representativo da população estudada, fazendo com que seus resultados fossem tomados como um retrato real de toda a população-alvo, utilizando a linguagem matemática para descrever as causas do fenômeno e as relações entre variáveis inerentes ao objeto da investigação. Com essa duplicidade de abordagens pode-se classificar a pesquisa, como sendo uma pesquisa do tipo qualitativa-quantitativa (Cervo, Bervian, \& Silva (2007).

Quanto a seleção das amostras a pesquisa caracteriza-se por uma amostragem estratificada, na medida em que após selecionados os centros de fitness foi definido um grupo distinto de sujeitos, os instrutores, para os quais a investigação propôs questões específicas (Thomas, Nelson, \& Silverman, 2009).

Considerando que o objetivo da pesquisa era construir um instrumento para avaliação da qualidade dos serviços prestados por centros de fitness na cidade do Rio de Janeiro sob a ótica dos instrutores, foi necessária a definição dos centros de fitness nos quais a abordagem dos sujeitos seria feita.

Assim, foi adotado como critério de inclusão a condição de fazer parte do conjunto de empresa com natureza de pessoa jurídica, devidamente registradas no órgão de classe, Conselho Regional de Educação Física - CREF/RJ-ES, independente do porte e localização, tomando como base o mês de novembro de 2016, para busca das informações no portal eletrônico do CREF/RJ-ES.

Um total de 1271 empresas foram consideradas como amostra da pesquisa e, após verificação da situação de regularidade quanto à condição de pleno funcionamento (ativa), e em relação as obrigações de pagamento das anuidades (regular), foram excluídas 249 empresas, restando 1022.

Em seguida foram excluídos da amostra, 157 registros de empresas, por serem profissionais individuais registrados na figura jurídica denominada MEI - Microempreendedor Individual, inadequados ao foco da investigação. Restaram assim, 865 centros de fitness na cidade do Rio de Janeiro que passaram a compor a amostra final da pesquisa.

A construção / adaptação do instrumento abrangeu dois tipos de procedimentos: (a) teórico, ligado as adaptações terminológicas e (b) empírico, com a aplicação do Teste de Clareza de Zequinão \& Cardoso (2013) para verificar sua aplicabilidade na coleta dos dados de tal modo a garantir que diferenças nas respostas equivaleriam a diferenças nas percepções e pontos de vista dos sujeitos, e não a diferenças interpretativas das questões.

No procedimento teórico foi feita a substituição de terminologias por outras relacionadas as especificidades de serviços oferecidos por centros de fitness, além de acrescentar itens abordando a acessibilidade de pessoas com mobilidade reduzida, exigência definida tanto por legislação específica no Brasil (Brasil, 2015) como também por normatização 
igualmente destinada ao atendimento deste segmento da sociedade (ABNT, 2015).

Feito isso, após as adaptações no instrumento original, o mesmo passou a conter 40 itens, cujas opções de respostas eram compreendidas numa escala do tipo Likert, entre $1-7$ onde 1 = discordo totalmente até o $7=$ concordo totalmente). Foram enviados convites à participação voluntária para $25 \%$ dos 865 centros de fitness equivalente a 216 empresas. Desses, responderam positivamente ao contato, aceitando participar voluntariamente, 207 profissionais que corresponderam a $95,8 \%$ de aceitação efetiva.
No procedimento empírico, de verificação da inteligibilidade do instrumento, foi realizada prétestagem junto a 10 informantes integrantes do grupo amostral, selecionados pelo critério de conveniência, imediatamente após a aceitação de participação por meio da ferramenta psicométrica denominada Teste de Clareza (Zequinão \& Cardoso, 2013).

Como resultados desse teste obteve-se o índice médio de $94 \%(\mathrm{DP}=0,84)$, superior, portanto, ao valor de $90 \%$, considerado minimamente aceitável por Alexandre \& Coluci (2011); Zequinão \& Cardoso (2013), e descrito na tabela A.

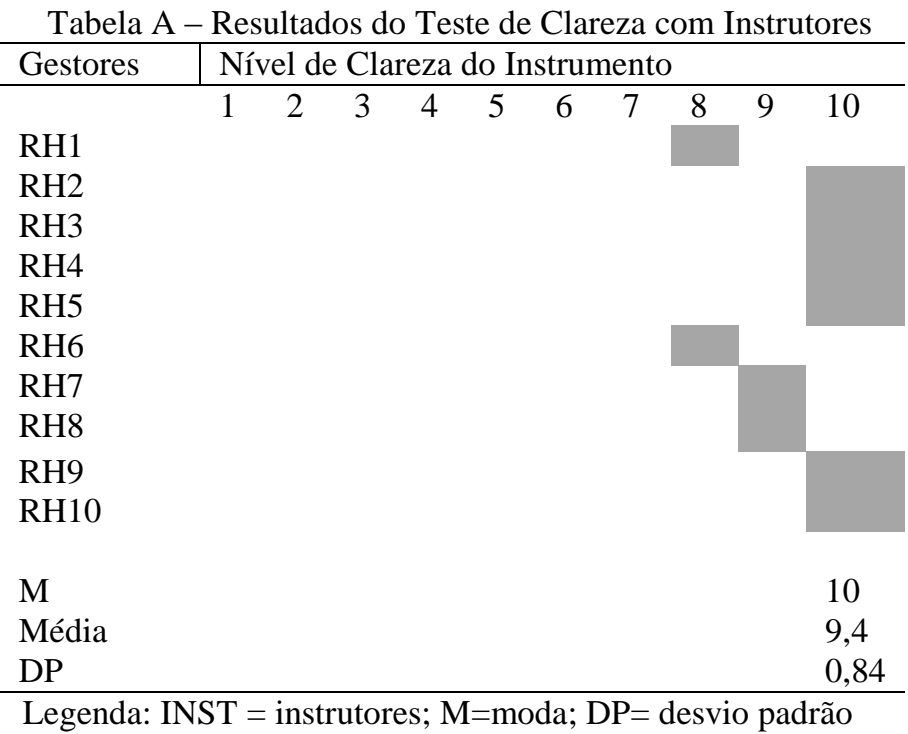

Após essa validação foram enviados os questionários aos demais componentes da amostra, com prazo para devolução dos mesmos definido para a $2^{\mathrm{a}}$. quinzena de abril/2017. Expirado esse prazo, obteve-se 186 devoluções, compondo participação efetiva de $89,9 \%$. Desse total foram eliminados 23 instrumentos $(12,3 \%)$ que apresentaram uma ou mais questões sem marcação de resposta e/ou com marcações em duplicidade num mesmo item, reduzindo o total de instrumentos válidos para 164 , equivalente a $87,7 \%$ de resposta efetiva.
Permitiu-se uma margem de um erro amostral de 5\% ( $p>0,05)$ e um nível de confiança de $90 \%$, considerando assim a amostra adequada ao desenvolvimento da pesquisa (Hair Jr., et al., 2009).

Assume-se aqui a autoria da distribuição dos itens do instrumento pelas dimensões adotadas na pesquisa de Quaresma (2008), propostas por Taveira, James, Karsh, \& Sainfort (2003) e relacionadas a programas de implantação da qualidade em empresas de diferentes segmentos, descritas no quadro 1.

Quadro 1 - Divisão dos Itens pelas Dimensões do Modelo de Taveira, James, Karsh, \& Sainfort (2003)

\begin{tabular}{|l|l|}
\hline Dimensão & Numeração das Questões Respectivas \\
\hline i. Suporte e Supervisão & $1,2,3,11,12,23,25,26,30,32,35$. \\
\hline ii. Orientação para a Tarefa & $6,7,14,15,17,18,21,22,27,31,33,34,39$. \\
\hline iii. Definição da Tarefa & $4,8,9,10,20,28,29,36$. \\
\hline iv. Inovação & $5,13,16,19,24,37,38,40$ \\
\hline
\end{tabular}

Fonte: a pesquisa 


\section{Procedimentos Estatísticos}

Considerando os dados colhidos junto aos instrutores adotou-se como recurso estatístico, na caracterização dos sujeitos, a estatística descritiva, especificamente: frequência (n); percentagem (\%) e; Moda (M). Além disso, para verificação do nível de representatividade das médias encontradas adotou-se o cálculo do coeficiente de variação (CV), descrevendo assim a homogeneidade desses dados, o que segundo Pestana \& Gageiro (2014) pode ser considerado baixo e, portanto, adequado, quando apresenta valores iguais ou menores a $30 \%$.

No tratamento dos dados específicos foi utilizado o software estatístico Statistical Package for the Social Sciences ${ }^{\circledR}\left(\right.$ SPSS $\left.^{\circledR}\right)$, na versão 22.0.

No que tange ao tratamento das notas atribuídas a cada um dos itens do instrumento, foram adotadas como técnicas estatísticas o cálculo da média e seus respectivos desvios-padrão, além da testagem de normalidade da amostra, para o qual adotou-se o teste de Kolmogorov-Smirnov Z.

Para o tratamento das respostas específicas foi adotada como técnica estatística a Análise Fatorial Exploratória (AFE), que permite não somente descobrir a estrutura fatorial subjacente a um conjunto de variáveis, mas também reduzir números elevados de fatores a apenas algumas dimensões, sem perda da qualidade e aplicabilidade da versão original (Hair Jr. et al, 2009; Carvalho, 2017).

Como método de extração da variância total foi usada a análise fatorial das componentes principais, que explica o máximo de variância possível e não unicamente aquela que é comum. Em seguida, para avaliar a adequabilidade dos dados para uso da AFE adotou-se os testes de Keiser-Meyer-Olkin (KMO) e Bartlett (BTS), realizando a análise pelo método de componentes principais com matriz rotacionada VARIMAX, que permite a simplificação da interpretação dos fatores, minimizando o número de itens com grande peso em um fator. Consequentemente, na escolha do número de fatores, optou-se pelo critério de Normalização de Kaiser, assumindo que os fatores retidos deveriam ter autovalores maiores que 2 (Hair Jr., et al, 2009).

\section{Análise e Discussão Resultados}

Apresenta-se inicialmente na tabela B os resultados ligados à caracterização desses sujeitos seguidos da respectiva análise. Esses dados, embora não sendo objetivo precípuo da investigação, revelaram peculiaridades importantes sobre a atuação desses profissionais nas empresas fitness onde atuam.

Tabela B - Moda, frequência, porcentagem das variáveis de caracterização dos Instrutores

\begin{tabular}{|c|c|c|c|c|}
\hline & Moda & Frequência & & $(\%)$ \\
\hline Idade (anos) & $31-40$ & $\begin{array}{l}21-30 \\
31-40\end{array}$ & $\begin{array}{l}50 \\
75\end{array}$ & $\begin{array}{l}30,5 \\
45,7\end{array}$ \\
\hline Sexo & Masculino & $\begin{array}{l}\text { Masculino } \\
\text { Feminino }\end{array}$ & $\begin{array}{l}84 \\
80\end{array}$ & $\begin{array}{l}51,2 \\
48,8\end{array}$ \\
\hline $\begin{array}{l}\text { Tempo Graduação em Educação } \\
\text { Física (anos) }\end{array}$ & $6-10$ & $\begin{array}{l}6-10 \\
11-15 \\
16-20\end{array}$ & $\begin{array}{l}55 \\
25 \\
14\end{array}$ & $\begin{array}{l}33.5 \\
15,2 \\
8,5\end{array}$ \\
\hline Pós-Graduação & Sim & $\begin{array}{l}\text { Sim } \\
\text { Não }\end{array}$ & $\begin{array}{l}110 \\
54\end{array}$ & $\begin{array}{l}67,1 \\
32,9\end{array}$ \\
\hline Pós-Graduação & $\begin{array}{l}\text { Musculação e } \\
\text { Personal Training }\end{array}$ & $\begin{array}{l}\text { Musculação e Personal } \\
\text { Training }\end{array}$ & 65 & 38,0 \\
\hline Mais de uma Pós-Graduação & Não & Não & 118 & 72,0 \\
\hline Mestrado & Não & Não & 0 & 91,5 \\
\hline Doutoramento & Não & Não & 164 & 100 \\
\hline Tempo de Atuação (anos) & $1-5$ & $\begin{array}{l}1-5 \\
6-10\end{array}$ & $\begin{array}{l}71 \\
42\end{array}$ & $\begin{array}{l}43,3 \\
25,6\end{array}$ \\
\hline Atividades em que atua & Personal Training & $\begin{array}{l}\text { Musculação } \\
\text { Personal Training }\end{array}$ & $\begin{array}{l}110 \\
130\end{array}$ & $\begin{array}{l}18,3 \\
21,6\end{array}$ \\
\hline
\end{tabular}

Fonte: o autor 
Quanto as idades dos profissionais, obteve-se predominância do intervalo 31 - 40 anos com incidência de $45,7 \%$ e que, associada ao grupo 21-30 anos, integralizou $76,2 \%$ do total de sujeitos. Estes números evidenciam na amostra estudada uma atuação profissional na dimensão operacional dessas empresas desempenhada predominantemente por "adultos jovens" segundo IBGE (2017). Este perfil etário reforça a ideia de que vitalidade e jovialidade são ingredientes relevantes da carreira em função das demandas físico-estruturais necessárias ao desempenho profissional.

Estes números corroboram os achados de Antunes (2007) que, estudando o perfil de instrutores de ginástica e musculação na cidade de São Paulo, evidenciou maior incidência de profissionais entre 2135 anos com decréscimo numérico a partir dessa idade. Nesse estudo, destacou-se a importância atribuída pelos sujeitos à dimensão estética no exercício profissional quando reportam o aspecto "boa aparência" como importante para 84,62\% dos instrutores. Em outro estudo, desenvolvido por Campos (2015), ao analisar o perfil de instrutores de fitness, os resultados corroboram o que aqui apresenta-se em relação à idade desses profissionais, com predominância compreendida entre 21-37 anos.

$\mathrm{Na}$ estratificação por sexo, obteve-se predominância discreta do sexo masculino $(51,2 \%)$ para esta atividade profissional, contradizendo a proporção de $47,7 \%$ de homens e $52,3 \%$ de mulheres na população do Rio de Janeiro (IBGE, 2017), embora essa distribuição seja corroborada pela predominância masculina no exercício profissional no Rio de Janeiro, descrita por Proni (2010) com 68\% de homens e 32\% de mulheres. Da mesma forma, Campos (2015) numa análise do perfil de instrutores de fitness ratifica os resultados da presente pesquisa, relatando $55 \%$ de homens e $45 \%$ de mulheres atuando na mesma cidade.

Quanto ao tempo de graduação em Educação Física, obteve-se a predominância do intervalo entre 6-10 anos com 33,5\%, que somado ao grupo anterior (1-5 anos), com $24,4 \%$, totaliza $68,9 \%$. Antunes (2007) corrobora esses números em pesquisa supracitada, com $23,1 \%$ com menos de 2 anos de experiência no trabalho, $36,9 \%$ entre $2-5$ anos, $27,7 \%$ com 6-10 anos e, apenas, 10,8\% com mais de 10 anos de exercício profissional. Esses dados evidenciam prevalência de atuação por no máximo 10 anos após ingressar no mercado, denotando uma fragilidade no exercício profissional, na medida em que a legislação previdenciária exige o trabalho por período mínimo de 35 anos para os homens e 30 para mulheres para fazer jus à aposentadoria (BRASIL, 2017).

Logo, se predomina o exercício profissional durante tempo máximo de 10 anos, há que se pensar na possibilidade do segmento fitness, o que mais emprega bacharéis em Educação Física no Brasil e no Rio de Janeiro, ser destinado apenas a jovens o que impacta negativamente as perspectivas de futuro nas carreiras dessas pessoas.

Sobre aprofundamento nos estudos por meio de especializações, $67,1 \%$ declaram ter cursado especialização no nível lato-sensu enquanto 32,9\% nada fizeram após a graduação, sinalizando para uma potencial desatualização de conhecimentos. Quando indagados sobre formações no nível stricto-sensu (mestrado e/ou doutoramento), apenas 8,4\% declaram ter cursado o mestrado e nenhum declarou chegar ao nível de doutorado, configurando praticamente nenhum interesse pela visão investigativa do próprio trabalho, o que sugere que a extensa produção científica abordando o segmento fitness não é desenvolvida por quem nele efetivamente atua.

Esses números se opõem aqueles encontrados por Antunes (2007) no estado de São Paulo/Brasil, com incidência de $15,4 \%$ cursando pós-graduação latosensu. Vieira \& Carneiro Jr. (2010), em pesquisa semelhante no estado de Minas Gerais - Brasil, encontraram $23 \%$ dos profissionais atuantes em 24 centros de fitness cursando ou tendo cursado uma pósgraduação lato-sensu. Além disso, os achados de Antunes (2007), Pereira \& de Paula (2007) e Vieira \& Carneiro Jr. (2010) corroboram a incidência nula $(0 \%)$ de participação dos instrutores atuantes em centros de fitness, quanto à inserção em algum tipo de programa de pós-graduação stricto sensu.

Quanto as preferências por especializações, obteve-se a maior incidência de procura, pelo curso de "Musculação e Personal Training" com 38\% das escolhas alinhada, portanto, ao crescimento numérico nos centros de fitness da oferta de treinamento personalizado. Este crescimento acompanha a expansão da rede de academias Smar Fit ${ }^{\circledR}$, que tem como foco a oferta de locação de espaços físicos para o treinamento de força e as atividades aeróbicas indoor, sem que haja exigência da presença de um profissional da própria empresa, e, por isso mesmo, amplamente utilizada para a prestação desse serviço por treinadores personalizados externos, (SmartFit, 2017).

No que diz respeito a área de maior incidência de atuação dos instrutores, obteve-se a opção 
"treinamento personalizado" (personal training) com $21,6 \%$, seguida da área de "musculação" com 18,3\% do total de opções.

Esses dados apresentam alinhamento com as escolhas pelas especializações descritas no item anterior, ratificando a realidade do mercado fitness na medida em que as 2 maiores redes de centros de fitness brasileiras, Smar Fit $^{\circledR}$ e Bodytech ${ }^{\circledR}$, respectivamente com 277 e 103 unidades no país e 28 e 20 no Rio de Janeiro, têm planos específicos para entrega a clientes de treinamento personalizado por profissionais que não facam parte de seus quadros funcionais com vínculo empregatício (SmartFit, 2017; Bodytech, 2017).

\section{Análise Descritiva}

Apresenta-se na tabela $\mathrm{C}$ a média das notas atribuídas pelos instrutores, seus respectivos desvios padrão e os limites superior e inferior encontrados, quanto à normalidade da amostra, obtidos a partir do teste de Kolmogorov-Smirnov Z. Pelo fato de nenhuma dimensão apresentar valor estatisticamente significativo $(\mathrm{p}>0,05)$, a amostra caracterizou-se como tendo distribuição normal.

Tabela C - Média e desvio padrão das pontuações atribuídas pelos instrutores nas dimensões propostas por James, Karsh \& Sainfort (2003), limites superior e inferior do teste de normalidade da amostra de Kolmogorov-Smirnov Z

\begin{tabular}{l|l|l|l}
\hline $\begin{array}{l}\text { Dimensões de Taveira, James, Karsh \& Sainfort } \\
\text { (2003) }\end{array}$ & Média (*) & Desvio Padrão & $\begin{array}{l}\text { Kolmogorov- } \\
\text { Smirnov Z }\end{array}$ \\
\hline Suporte e Supervisão & 4,42 & 0,84 & \\
\hline Orientação para Tarefa & 3,92 & 1,14 & $0,42-0,73$ \\
\hline Definição da Tarefa & 4,64 & 0,67 & \\
\hline Inovação & 4,81 & 0,74 & \\
\hline
\end{tabular}

(*) todas as dimensões apresentaram distribuição gaussiana (Teste de Kolmogorov Smirnov Z) $\mathrm{p}>0,05$.

Como pode-se observar, a distribuição dos valores obtidos pela aplicação do instrumento aos instrutores teve sua maior frequência de valoração na dimensão "inovação" $(\mathrm{M}=4,81$ e $\mathrm{DP}=0,74)$, seguida de "definição da tarefa" (M=4,64 e DP=0,67), "suporte e supervisão" (M=4,42 e $\mathrm{DP}=0,84)$ e, por último, "orientação para a tarefa" (M=3,92 e DP=1,14).

No que tange à estrutura fatorial extraída do instrumento original, consideramos válidos e aceitos os valores obtidos neste grupo amostral. Respaldamos tal afirmativa no posicionamento de Bido, Mantovani \& Cohen (2016), quando afirmam ser adequado e consistente, todas as vezes em que o primeiro fator extraído não-rotacionado tiver autovalor maior que 1 , o que no caso da amostra investigada apresentou autovalor $>2$. Tratando da consistência interna dos itens que compunham o instrumento original, e tomando como base os valores de Teste de Normalidade (KMO) encontrados nos resultados $(0,73)$, pode-se inferir com base em Figueiredo Filho \& Silva Júnior (2010); Pestana \& Gageiro (2014), que as dimensões propostas por James, Karsh, \& Sainfort (2003) mostraram-se adequadas para utilização como base para a construção do modelo conceitual objetivado na pesquisa.

\section{Análise Fatorial Exploratória}

Na construção do modelo conceitual aplicável a profissionais atuantes nesses centros de fitness, optouse pela redução do instrumento original ( $n^{\circ}$. de itens) e consequente reorganização das dimensões originais, buscando otimizar a aplicação sem perda de qualidade e utilizando para isso, a AFE como técnica. Assim, no que tange à verificação da existência de uma estrutura fatorial subjacente ao instrumento original e otimização do número de itens e fatores, assumiu-se, primeiramente, o resultado do teste de Kaiser-MeyerOlkin (KMO) igual a 0,733, o que permite afirmar que a dimensão da amostra também apresentou adequacidade na aplicação da técnica por seus valores situarem-se entre 0,5 e 1,0 .

Quanto à redução do número de itens, e sua interferência nos resultados da investigação, reiteramos posição de Melo \& Bianchi (2015) quando afirmam que instrumentos extensos podem gerar resultados indevidos e pouco úteis, enquanto instrumentos curtos demais podem deixar de capturar o que era essencial à investigação. Em síntese, estes autores recomendam que se faça o melhor com o 
instrumento mais adequado para quem o aplica, e mais agradável possível para quem o responde.

Assim, e após a aplicação da AFE nos 40 itens que compunham o instrumento original, distribuídos pelas 4 dimensões de Taveira, James, Karsh \& Sainfort (2003), seguida de rotação ortogonal Varimax, foram extraídos 21 itens que explicam $61,70 \%$ da variância comum dos dados distribuídas por 5 dimensões. Porém, nesse tratamento dos dados, verificou-se nas dimensões 1 e 2 , respectivamente, "autonomia, senso de equipe e agilidade" e "eficiência, eficácia e inovação", uma covariância média negativa entre itens que viola os pressupostos do modelo de confiabilidade. Tal descoberta levou à exclusão de uma questão na primeira dimensão citada (38) e duas $(2,14)$ na segunda, fazendo com que elas não compusessem o instrumento final.

Feito isso, e após a reorganização a partir do instrumento original, emergiu uma nova configuração do instrumento, no qual foram distribuídos os 18 itens, dessa vez por 5 dimensões, que pode ser visualizado na tabela $\mathrm{D}$.

Tabela D - Distribuição dos Itens para os instrutores nas novas dimensões, AFE, teste KMO, $\alpha$ de Cronbach

\begin{tabular}{|c|c|c|c|c|}
\hline Fatores & Itens & \% Variância & $\begin{array}{l}\text { \% Variância } \\
\text { acumulada }\end{array}$ & $\begin{array}{l}\alpha \quad \text { (alpha } \\
\text { Cronbach) }\end{array}$ \\
\hline $\begin{array}{l}\text { 1. Autonomia, senso de ec } \\
\text { e agilidade }\end{array}$ & $\begin{array}{l}\text { lipe } 24,30,34,35 \text {, } \\
37,40\end{array}$ & 27,15 & 27,15 & 0,870 \\
\hline $\begin{array}{l}\text { 2. Eficiência, eficácia } \\
\text { inovação }\end{array}$ & e $13,16,19$ & 10,61 & 37,76 & 0,815 \\
\hline 3. Diretrizes e resultados & $3,8,10$ & 8,98 & 46,74 & 0,822 \\
\hline 4. Ambiência e prazos & $26,27,28,32$ & 7,90 & 54,64 & 0,737 \\
\hline 5. Solidariedade e desafios & 20,25 & 7,06 & 61,70 & 0,793 \\
\hline
\end{tabular}

\section{$\mathrm{KMO}=0,733$}

Como pode-se observar, o fator 1 explica $27,15 \%$ do total da variância comum dos dados e satura 7 itens $(24$, $30,34,35,37,38,40)$. O fator 2 explica $10,61 \%$ da variância comum dos dados e satura 5 itens $(2,13,14$, 16,19). O fator 3 que explica $8,98 \%$ da variância comum dos dados, satura 3 itens $(3,8,10)$. Já o fator 4 explica $7,90 \%$ da variância comum e satura 4 itens $(26,27,28$, 32). $\mathrm{O}$ fator 5 explica $7,06 \%$ da variância comum dos dados e satura 2 itens $(20,25)$.

Portanto, levando em conta os valores encontrados para $\alpha$ de Cronbach (consistência interna) apresentados na mesma tabela, que variam entre 0,74 na dimensão "ambiência e prazos" e 0,87 na dimensão "autonomia, senso de equipe e agilidade", considera-se válidas todas estas dimensões pelo fato de satisfazerem as exigências mínimas de valores maiores que $0,70 \quad(\alpha>0,70)$, tornando-as estatisticamente adequadas segundo Pestana \& Gageiro (2014). Diante desses dados, e tomando Bido, Mantovani, \& Cohen (2016) como referência, assume-se ter atendido e superado as quantidades consideradas mínimas para aplicação adequada da técnica, ou seja, um número superior a 100 (foram 164 profissionais) com um mínimo de 5 itens para cada um, o que confere robustez e consistência aos resultados.
Assim, foi criado o novo instrumento, apresentado na figura 1, composto agora por 18 itens, distribuídos por 5 dimensões, com saturação de $61,7 \%$ da variância comum dos dados, autovalor > 2 e $\mathrm{KMO}=0,733$, permitindo-nos afirmar que itens e respectivas dimensões são tecnicamente adequados e consistentes. Além disso, e levando em conta os valores encontrados para o alfa de Cronbach situados entre o valor mínimo de 0,74 na dimensão "ambiência e prazos" e máximo de 0,87 na dimensão "autonomia, senso de equipe $e$ agilidade", é possível afirmar também que os mesmos atendem as exigências integralmente descritas pela literatura de referência, alinhando-se positivamente ao estudo de Quaresma (2008), em relação ao instrumento aplicado também aos instrutores, cuja variação nos valores do $\alpha$ de Cronbach posicionaram-se entre $0,75 \mathrm{e}$ 0,83 , validando com isso seu instrumento final.

Além disso, encontramos consonância com pesquisa empreendida por Almeida, Santos \& Costa (2010), ao avaliarem o desempenho da qualidade na saúde pública na cidade de Guaratinguetá no estado de São Paulo/Brasil por meio da aplicação de um questionário nas suas UBS - Unidades Básicas de Saúde quando, medindo a confiabilidade da escala e dos resultados obtidos com ela, obteve alfa de Cronbach, entre 0,70 - 
0,84, confirmando a confiabilidade da escala adotada, relevância e robustez na pesquisa realizada. Streiner (2003) descreve que o valor mínimo aceitável para o alfa de Cronbach é 0,70, já que abaixo desse valor a consistência interna da escala utilizada é considerada baixa. Para ele, valores aceitáveis situam-se na faixa de 0,80 e 0,90 . Acima dessa faixa pode-se considerar que há redundância, ou seja, vários itens estão medindo exatamente o mesmo elemento de um determinado constructo e, portanto, esses itens devem ser eliminados.
Portanto, a consistência interna encontrada permitenos inferir que as dimensões, e seus respectivos itens, gerados a partir da AFE, são tecnicamente válidas e adequadas (Oviedo \& Campo-Arias, 2005; Quaresma, 2008; Thomas, Nelson \& Silverman, 2009; Pestana \& Gageiro, 2014), o que nos permite afirmar que o modelo conceitual construído é igualmente válido e eficaz, do ponto de vista da sua utilização com instrutores atuantes em centros de fitness no Rio de Janeiro.

\section{Figura 1 - Novo Intrumento Específico para Instrutores após AFE}

\begin{tabular}{|ll|}
\hline EM RELAÇÃO A ACADEMIA ONDE VOCÊ ATUA, COMO PERCEBE OS SEGUINTES ITENS? \\
\hline DIMENSÃO 1 (autonomia, senso de equipe e agilidade) \\
\hline 1) & Esta empresa promove nos seus funcionários uma cultura de inovação. \\
\hline 2) & Nesta empresa existe uma política de não adiamento sucessivo das tarefas. \\
\hline 3) & Os funcionários desta empresa podem usar a iniciativa própria para realizar as suas funções. \\
\hline 4) & Nesta empresa as responsabilidades dos gestores estão claramente definidas. \\
\hline 5) & Quando um novo trabalhador é admitido, os outros funcionários ajudam-no a sentir-se integrado. \\
\hline 6) & Os funcionários têm orgulho de trabalhar nesta empresa.
\end{tabular}

\section{DIMENSÃO 2 (eficiência, eficácia e inovação)}

1) Nesta empresa existe uma cultura para implementar ideias novas e diferentes.

2) Nesta empresa as tarefas executadas de modo diferenciado são valorizadas pela gestão.

3) Os gestores desta empresa dão credibilidade às ideias propostas pelos funcionários.

\section{DIMENSÃO 3 (diretrizes e resultados)}

1) Os gestores desta empresa, normalmente, elogiam os funcionários quando fazem algo bem feito.

2) Nesta empresa existe uma constante preocupação em fazer cumprir os regulamentos.

3) Esta empresa é um local de trabalho altamente eficaz e orientado.

\section{DIMENSÃO 4 (ambiência e prazos)}

1) Nesta empresa os funcionários não têm tempo para relaxar.

2) Nesta empresa pessoas com deficiências na locomoção não têm pleno acesso a todos os serviços disponíveis.

3) Nesta empresa há sempre muita urgência para concluir as respectivas tarefas.

4) Nesta empresa os gestores mantêm uma vigilância apertada sobre os funcionários.

\section{DIMENSÃO 5 (solidariedade e desafios)}

1) O trabalho que desempenho nesta empresa é realmente um desafio.

2) Nesta empresa os funcionários interessam-se pessoalmente uns pelos outros. 


\section{Conclusões}

Considerando que a economia brasileira, assim como outras, é movida pelos serviços e que estes são o resultado da ação de múltiplos stakeholders, tornase imperativa a atenção e investimentos progressivamente maiores na prestação de serviços de qualidade, ainda que as demandas por eles sejam diferentes, o que exige controle minucioso gerado por um modelo de gestão baseado em evidências.

Sob esse ponto de vista, uma gestão com esse perfil deve, se pretende lograr sucesso, dedicar atenção as percepções de seus múltiplos atores, sobretudo aqueles que respondem pela entrega direta dos serviços aos clientes, quais sejam os instrutores. Nesse caso específico, os profissionais de Educação Física que atuam diretamente na relação de consumo clientes-empresas.

Sob o ponto de vista teórico conclui-se pela oferta a comunidade científica, nessa área de conhecimento, de um importante instrumento, específico e orientado a uma dimensão pouco estudada nas relações de consumo de serviços fitness, os instrutores, propiciando a abertura de uma perspectiva de novos estudos futuros sobre possíveis sintonias e dicotomias entre as percepções de quem entrega e recebe esses serviços.

Com isso, podemos inferir que o maior benefício de uma gestão atenta as percepções de diferentes stakeholders, é o monitoramento efetivo da qualidade dos serviços e a implementação das melhorias necessárias, e os maiores beneficiados são os próprios gestores, suas empresas e seus clientes.

Os gestores, pelo fato de disporem de dados consistentes, que os permitem decisões assertivas e pertinentes, baseadas naquilo que efetivamente precisa ser feito para gerar resultados melhores no negócio.

As empresas, pelo impacto direto dessas decisões nos seus resultados, tornando-as mais lucrativas e viabilizando sua sobrevivência no mercado do qual fazem parte a partir da criação de diferenciais que as tornem mais adequadas as demandas dos consumidores.

Finalmente, os clientes, que por força de consequência das decisões assertivas dos gestores em empresas que os consideram sua própria razão de ser, acabam recebendo serviços sob medida e capazes de atender as suas demandas, produzindo uma saudável aproximação entre expectativas e resultados em termos de serviços fitness.
No que tange aos objetivos da pesquisa, e considerando a lacuna de investigações voltadas a construir instrumentos para avaliar a qualidade dos serviços em centros de fitness na cidade do Rio de Janeiro sob a ótica dos instrutores, pode-se afirmar que o propósito foi alcançado plenamente e com o acréscimo de fornecer relevantes informações que permitiram um conhecimento maior sobre esses profissionais.

Pode-se verificar com a pesquisa que os instrutores são profissionais adultos-jovens, com predominância masculina, tempo de atuação praticamente limitado a 15 anos, ou seja, retratando a possibilidade de suas carreiras não poderem evoluir no exercício dessa atividade profissional. Além disso, a evidência de um número preocupante de profissionais desatualizados e sem cursar qualquer especialização, para os quais educação continuada e pesquisa não fazem parte do seu cotidiano, dado preocupante numa área de conhecimento que evolui contínua e rapidamente.

A área de treinamento de força é a mais procurada por esses profissionais para trabalhar e, por isso, sendo a que menos remunera, foi nítida a existência de um cenário propício para a desistência da profissão, o que, de fato, tem ocorrido sistematicamente no Rio de Janeiro.

Além disso, os resultados permitem concluir que a confiabilidade, bem como a estrutura fatorial encontrada no instrumento destinado aos instrutores, é boa e aceitável para a avaliação da qualidade de serviços, demonstrando uma condição psicométrica adequada. Com isso, pode-se inferir que o modelo proposto possui validade fatorial e consistência interna boa, autorizando-nos, portanto, sugerir sua utilização como instrumento para mensurar a percepção de qualidade dos serviços em centros de fitness na cidade do Rio de Janeiro, contribuindo de modo consistente para um avanço qualitativo nas práticas de gestão desses centros e permitindo entregas mais alinhadas com as expectativas dos seus clientes.

Por derradeiro, recomenda-se a aplicação do instrumento em tela em associação aqueles desenvolvidos sob a ótica de gestores e de clientes, com foco em centros de fitness na cidade do Rio de Janeiro, compondo assim uma saudável multidimensionalidade na avaliação da qualidade dos serviços dessas empresas e aproximando ainda mais a realidade dessa relação de consumo e da qualificação dos serviços prestados nesse segmento de negócios. 


\section{Referências}

ABNT. (2015). NBR 9050. Norma Brasileira para Acessibilidade a Edifcações, Mobiliário, Espaços e Equipamentos Urbanos, 3a. Brasília, Distrito Federal, Brasil. Acesso em 20 de fevereiro de 2017, disponível em

http://www.pessoacomdeficiencia.gov.br/app/sites/d efault/files/arquivos/\%5Bfield generico imagensfilefield-description\%5D 164.pdf

Alexandre, N. M. C.; Coluci, M. Z. O. (2011). Validade de Conteúdo nos Processos de Construção e Adaptação de Instrumentos de Medidas. Ciência \& Saúde Coletiva, 16 (7), pp. 3061-3068. Acesso em 21 de abril de 2017. disponível em https://www.scielosp.org/pdf/csc/2011.v16n7/30613068/pt.

Alexandris, K., Douka, S., Papadopoulos, P., \& Kaltsatou, A. (2008). Testing the role of service quality on the development of brand associations and brand loyalty. Managing Service Quality: An International Journal, 18(3), pp. 239-254. Acesso em 12 de maio de 2017, disponível em http://www.emeraldinsight.com/doi/abs/10.1108/096 04520810871865

Almeida, D., Santos, M. A. R. D., \& Costa, B. (2010). Aplicação do Coeficiente Alfa de Cronbach nos resultados de um questionário para avaliação de desempenho de saúde pública-XXX Encontro nacional de engenharia de produção. São Carlos.

Antunes, A. C. (2007). Mercado de Trabalho e Educação Física: Aspectos da Preparação Profissional. Revista de Educação, 10(10), pp. 141149.

Avourdiadou, S. \& Theodorakis, N. D. The development of loyalty among novice and experienced customers of sport and fitness centres. Sport Management Review. 17(4), pp. 419-431. acesso em 03 de janeiro de 2019, disponível em https://www.sciencedirect.com/science/article/pii/S1 44135231400014X.

Barreto, E. G., Santos, R. L., Gomes, M. L., Silva, L. B., \& Menezes, V. L. (2012). Aplicação do Método SERVQUAL na Avaliação da Satisfação de Clientes em uma Academia de Ginástica. (R. d.-G. UTPFPR, Ed.) Revista Gestão Industrial, 8(3). Acesso em 25 de julho de 2016, disponível em https://revistas.utfpr.edu.br/revistagi/article/view/939 1877

Batista, P. M., Joaquim, B., \& Carvalho, M. J. (2016). A Percepção de Competências dos Gestores Desportivos em Função da Experiência Profissional. Revista Brasileira de Ciências do Esporte, 38(1), pp. 50-57. Acesso em 25 de julho de 2017, disponível em http://www.scielo.br/pdf/rbce/v38n1/0101-3289rbce-38-01-0050.pdf

Berry, L., Parasuraman, A., \& Zeithaml, V. (1988). The Service Quality Puzzle. Business Horizons, 31, $\quad$ pp. 35-43. doi:https://doi.org/10.1016/0007-6813(88)90053-5

Bido, D. S., Mantovani, D. M., \& Cohen, E. D. (2016). Aplicações da Análise FAtorial Exploratória à Pesquisa na Área de Operação e Produção: Um Estudo em Publicações Nacionais e Internacionais. SIMPOI 2016 - Anais.

Bilhim, J. (2006). Gestão estratégica de Recursos Humanos. Lisboa, Lisboa, Portugal: UTL.

Bodytech. (2017). Bodytech Company. RJ, RJ, Brasil. Acesso em 02 de agosto de 2017, disponível em http://www.bodytech.com.br/Empresa

Brasil. (2015). Estatuto da Pessoa com Deficiência. Lei $n^{\circ}$ 13.146. Brasília, Distrito Federal, Brasil: Presidência da República - Casa Civil - SubChefia para Assuntos Jurídicos. Acesso em 20 de fevereiro de 2017, disponível em http://www.planalto.gov.br/ccivil_03/_ato2015-

2018/2015/lei/113146.htm

Brasil. (2017). Sistema de Legislação da Previdência Social. Brasília, Distrito Federal, Brasil. Acesso em 28 de julho de 2017, disponível em https://www.google.com.br/url?sa=t\&rct=j\&q=\&esrc $=\mathrm{s} \&$ source $=$ web $\& \mathrm{~cd}=1 \& \mathrm{cad}=\mathrm{rja} \&$ uact $=8 \& \mathrm{ved}=0 \mathrm{ah}$ UKEwjX9fOR17zVAhVCCpAKHR3rDRcQFggnM AA\&url=http $\% 3 \mathrm{~A} \% 2 \mathrm{~F} \% 2 \mathrm{Fwww}$.previdencia.gov.br $\% 2$ Flegislacao\%2F\&usg=AFQjCNEToRfoF7ZKCU _yu4cuv5It0avPeg

Campos, F. J. (2015). A Qualidade do Instrutor em Atividades de Grupo de Fitness. Tese de Doutoramento em Ciência do Desporto. Vila Real, Alto Douro, Portugal: UTAD. Acesso em 08 de maio de 2017, disponível em 
Avaliação da Qualidade de Serviços em Centros de Fitness no Rio de Janeiro: Proposta de Instrumento Específico para Instrutores

http://repositorio.utad.pt/bitstream/10348/4653/1/phd _fjacampos.pdf

Campos, L. M. (2007). Abordagem da Análise Conjunta no Processo Decisório de Aquisição do Serviço de Academia de Ginástica. Dissertação de Mestrado Executivo. RJ, Brasil: FGV.

Carlzon, J. (2005). A Hora da Verdade. (M. L. SILVEIRA, Trad.) SP, SP, Brasil: Sextante.

Carvalho, L. H. (2017). ABG Consultoria Estatística. Análise Fatorial: Uma Importante Técnica Multivariada. (http://www.abgconsultoria.com.br/blog/analisefatorial/, Ed.) São Paulo, SP, Brasil.

Cervo, A. L., Bervian, P. A., \& Silva, R. (2007), Metodologia Científica (6a. ed.). São Paulo, SP, Brasil: Pearson Prentice Hall.

Chelladurai, P., \& Chang, K. (2000). Targets and Standards of Quality in Sport Services. Sports Management Review, 3, 1-22. Acesso em 25 de março de 2016, disponível em http://www.sciencedirect.com/science/article/pii/S14 41352300700775

Chelladurai, P., Scott, F. L., \& Haywood-Farmer. (1987). Dimensions of fitness services: development of a model. Journal of Sport Management, 1, pp. 159172. Acesso em 13 de fevereiro de 2015

Chelladurai, P., (2014). Managing Organizations for sports and physical activity: a systems perspective. $4^{\text {th }}$. ed. Arizona: Holcomb Hathaway Publishers.

Chiavenato, I. (2014). O Novo papel dos Recursos Humanos nas Organizações (4a. ed.). SP, SP, Brasil: Manole.

Corrêa, H. L., \& Caon, M. (2009). Gestão de Serviços: Lucratividade por Meio de Operações e da Satisfação de Clientes (1a. ed.). SP, SP, Brasil: Atlas.

Corrêa, S. A., \& Ferreira, A. A. (2009). Estratégia Competitiva das Academias de Ginástica da Cidade de São Paulo. Facef Pesquisa, 12, pp. 63 - 76. Acesso em 08 de julho de 2015, disponível em http://periodicos.unifacef.com.br/index.php/facefpes quisa/article/view/5
CREF/RJ-ES. (2016). Consulta Cadastral de Pessoas Jurídicas. RJ, RJ, Brasil. Acesso em 29 de dezembro de 2016, disponível em http://spiderweb.cref1.org.br/spw/consultacadastral/t elaconsultapublicacompleta.aspx

Dias, D. M. (2006). Influência da qualidade/satisfação na academia de fitness de um corpo de bombeiro e suas implicações. Dissertação (Mestrado em Ciências do Desporto), 1, 1, 222. Porto, Porto, Portugal. Acesso em 14 de janeiro de 2015.

Farias, E. (2015). Qualidade nos Serviços: O Que os Clientes Pensam Sobre Isso? Revista Empresário Fitness \& Health(72), pp. 26-28. Acesso em 12 de maio de 2015, disponível em http://www.revistaempresariofitness.com.br/gestaocom-ciencia/qualidade-nos-servicos-o-que-osclientes-pensam-sobre-isso

Farias, E. (2016). Qualidade em Serviços Orientada a Resultados: Uma Proposta Estratégica para Empresas Fitness. Empresario Fitness \& Health. Acesso em 02 de abril de 2017, disponível em http://www.edvaldodefarias.com/qualidadeservicosre sultados.pdf

Farias, E., Quaresma, L. F., Vilaça-Alves, J. \& Neves, E. B. (2018). A Perspectiva dos clientes na Construção de um Instrumento para Avaliar a Qualidade dos Serviços em Centros de Fitness no Rio de Janeiro. RGNE - Revista de Gestão e Negócios do Esporte,3 (2), 140-159.

Farias, E., Quaresma, L. F., Neves, E. B. \& VilaçaAlves, J. (2018). Proposta de um Instrumento para Avaliação da Qualidade de Serviços em Centros de Fitness no Rio de Janeiro na Perspectiva dos Gestores. RIGD - Revista Intercontinental de Gestão Desportiva, 8 (2), 91-117.

Feire, T., \& Almeida, L. S. (2008). Metodologia da Investigação em Psicologia e Educação (5a. ed.). Lisboa, Lisboa, Portugal: Psiquilibrios.

Figueiredo Filho, D. B., \& Silva Júnior, J. A. (2010). Visão Além do Alcance: Uma Introdução à Análise Fatorial. (U. F. Pernambuco, Ed.) Opinião Pública, 16(1), pp. 160-185.

Fitzsimmons, J. A., \& Fitzsimmons, M. J. (2000). Administração de serviços: operações, estratégia e tecnologia de informação (2a. ed.). Porto Alegre: Bookman. 
Garbi, E. (2002). Alternative measures of performance for E- companies: a comparison of approaches. Journal of Business Strategies, 19(1a.), $1-17$.

Gerhardt, T. E., \& Silveira, D. T. (2009). Métodos de Pesquisa. Porto Alegre, Rio Grande do Sul, Brasil. Acesso em 29 de maio de 217, disponível em http://www.ufrgs.br/cursopgdr/downloadsSerie/derad 005.pdf

Gil, A. C. (2010). Como Elaborar Projetos de Pesquisa (5a. ed.). RJ: Atlas.

Grönroos, C. (2000). Service Management and Marketing: a Customer Relationship Management Approach. Chinchester, USA: John Wiley \& Sons, Lda.

Grönroos, C. (2007). Marketing: Gerenciamento e Serviços. RJ, RJ, Brasil: Elsevier.

Hair Jr., J. F., Black, W. C., Babin, B. J., Anderson, R. E., \& Tatham, R. L. (2009). Análise Multivariada de Dados (6a. ed.). Porto Alegre, Rio Gde. do Sul, Brasil: Artmed.

Howat, G. \& Assaker, G. (2013). The hierarchical effects of perceived quality on perceived value, satisfaction, and loyalty: Empirical results from public, outdoor aquatic centres in Australia. Sport Management Review. 16(3), pp. 268-284. acesso em 04 de janeiro de 2019, disponível em https://www.sciencedirect.com/science/article/pii/S1 441352312001167.

Howat, G. \& Assaker, G. (2016). Outcome quality in participant sport and recreation service quality models: Empirical results from public aquatuic centres in Australia hierarchical effects of perceived quality on perceived value, satisfaction, and loyalty: Empirical results from public, outdoor aquatic centres in Australia. Sport Management Review. 19(5), pp. 520-535. acesso em 04 de janeiro de 2019, disponível em

https://www.sciencedirect.com/science/article/pii/S1 441352316300043.

IBGE. (2014). ECONOMIA E EMPREGO: Em 2013, PIB cresce 2,3\% e totaliza $\mathrm{R} \$ 4,84$ trilhões. Relatório. RJ, RJ, Brasil. Acesso em 08 de julho de 2015 , disponível http://www.brasil.gov.br/economia-e- emprego/2014/02/em-2013-pib-cresce-2-3-e-totalizar-4-84-trilhões

IBGE. (2017). IBGE - Projeções e Estimativas da Populaçãodo Brasil e das Unidades da Federação. IBGE. Brasília - Distrito Federal: IBGE. Acesso em 25 de julho de 2017, disponível em http://www.ibge.gov.br/apps/populacao/projecao/

IBGE. (2017). Pesquisa Anual de Serviços - 2014. Acesso em 24 de julho de 2017, disponível em IBGE - Brasil em Síntese: http://brasilemsintese.ibge.gov.br/servicos

IHRSA. (2016). International Health, Racquet \& Sportsclub Association - Global Report 2016. IHRSA. IHRSA. Acesso em 25 de março de 2017

Kim, D., \& Kim, S. (1995). QUESC: an instrument for assessing the service quality of sport centers. Journal of Sport Management, 9(2), pp. 209-220. Acesso em 10 de julho de 2014.

Ko, J., \& Pastore, D. (2005). A Hierarchical Model of Service Quality in the Recreational Sport Industry. Sport Marketing Quarterly, pp. 84-97. Acesso em 15 de abril de 2015, disponível em https://www.researchgate.net/profile/Yong_Jae_Ko/p ublication/285816752_A_hierarchical_model_of_ser vice_quality_for_the_recreational_sport_industry/lin ks/5667078508ae34c89a02207c.pdf

Kotler, P., \& Armstrong, G. (2015). Princípios de Marketing (15a. ed.). SP, SP, Brasil: Pearson Education - Br.

Kotler, P., \& Keller, K. L. (2006). Administração de Marketing (12 ed.). São Paulo, SP, Brasil: Pearson Prentice Hall.

Ladhari, R. (2009). A Review of Twenty Years of SERVQUAL Research. International Journal of Quality and Service Sciences, 1(2), pp. 172-198. Acesso em 15 de fevereiro de 2017, disponível em http://www.emeraldinsight.com/10.1108/175666909 10971445

Linhares, L. M., \& Freitas, A. L. (2011). Avaliação da Qualidade de Serviços em Academias de Ginástica: Um Estudo Experimental. ENEGEP 2011, 1, 6. (E. 2011, Ed.) Belo Horizonte, Minas Gerais, Brasil. Acesso em 04 de fevereiro de 2015 
Avaliação da Qualidade de Serviços em Centros de Fitness no Rio de Janeiro: Proposta de Instrumento Específico para Instrutores

Lopes, J. C. (2014). Gestão da Qualidade: Decisão ou Constrangimento Estratégico. Dissertação de Mestrado em Estratégia Empresarial. Lisboa, Portugal: Universidade Européia - Laureate International Universities. Acesso em 10 de abril de 2017,disponível em https://comum.rcaap.pt/bitstream/10400.26/13214/1/ Disserta\%C3\%A7\%C3\%A3o\%20de\%20M-EE\%20$\% 20$ Gest $\%$ C $3 \%$ A3o\%20da\%20Qualidade\%20\%20Janice\%20Lopes\%2050029662.pdf

Lovelock, C., \& Wright, L. (2003). Serviços: Marketing \& Gestão (3 ed., Vol. 1). São Paulo, SP, Brasil: Saraiva.

Lovelock, C., Wirtz, J., \& Hemzo, M. A. (2011). Marketing de Serviços: Pessoas, Tecnologia e Estratégia (7a. ed.). SP, SP, Brasil: Pearson Prentice Hall.

Macedo, I. I., Rodrigues, D. F., Johann, M. E., \& Cunha, N. M. (2003). Aspectos Comportamentais da Gestão de Pessoas. RJ: FGV/RJ.

Marconi, M. A., \& Lakatos, E. M. (2009). Fundamentos da Metodologia Científica. São Paulo, SP, Brasil: Atlas.

Mariano, S. G. (2017). Qualidade em Serviços e Programas de Atividades Físicas na visão de Clientes, Instrutores e Gestores - Construção e Validação do Instrumento SQFSbr. Dissertação (Mestrado em Ciências), São Paulo, USP, Brasil. Acesso em 04 de janeiro de 2018

Melo, V. W., \& Bianchi, C. S. (2015). Discutindo Estratégias para a Construção de Questionários como Ferramenta de Pesquisa. R.B.E.C.T, 8(3), pp. 43-59.

Marras, J. P. (2000). Administração de Recursos Humanos: do Operacional ao Estratégico (3a. ed.). SP, SP, Brasil: Futura.

Morgan, N. A., \& Rego, L. L. (2006). The Value of Different Customer Satisfaction and Loyalty Metrics in Predicting Business Performance. Marketing Science, 25(5), pp. 426-439. Acesso em 17 de fevereiro de 2015.

Motta, E. M., \& Moraes, M. C. (2017). Proposta de Atributos de Serviços e Indicadores de Desempenho para Academias Fitness. Podium Sports, Leisure an Tourism Review, 6(1), 124-145. Acesso em 25 de maio de 2017, disponível em http://www.podiumreview.org.br/ojs/index.php/rgesp orte/article/view/167

Najafzadeh, M. R. \& Shiri, F. (2015). The Relationship between Service Quality and Perceived Value with Customer Loyalty and Aerobic Fitness Clubs in Tabriz. International Journal of Physical Education, Sports and Health. 1(6), pp. 69-73. Acesso em 04 de janeiro de 2019, disponível em http://www.kheljournal.com/archives/2015/vollissue 6/PartB/1-5-70.pdf .

Oliver, R. L. (1993). Cognitive, Affective, and Attribute Bases of the Satisfaction Response. Journal of Consumer Research, 20. Acesso em 28 de dezembro de 2016, disponível em https://pdfs.semanticscholar.org/4908/3c52cdc21692 75117e578e9ae33329d9e69f.pdf

Ortner, H. M. (2000). The human factor in quality management. (D. U. Technology, Ed.) Accreditation and Quality Assurance, 5(4), pp. 130-141. doi:10.1007/s007690050432

Osti, L. R. (2009). Atributos de Satisfação como Determinantes da Lealdade de Clientes de Academias no Brasil. Dissertação de Mestrado em Gestão do Desporto. Lisboa, Portugal, Portugal: Faculdade de Motricidade Humana. Acesso em 20 de maio de 2017, disponível em http://www.repository.utl.pt/bitstream/10400.5/1512/ 8/OSTI\%202009_tese.pdf

Oviedo, H. C., \& Campo-Arias, A. (2005). Aproximación al uso del coeficiente alfa de Cronbach. Revista Colombiana de Psiquiatría, 34(4), pp. 572-580.

Parasuraman, A., Zeithaml, V. A., \& Berry, L. L. (1985). A Conceptual Model of Service Quality and its Implications for Future Research. Jounal of Marketing, 49, pp. 41-50. Acesso em 02 de abril de 2016, disponível em http://www.jstor.org/stable/1251430?loggedin=true \&seq=2\#page_scan_tab_contents

Parasuraman, A., Zeithaml, V., \& Berry, L. (1988). SERVQUAL: A multiple-item scale for measuring consumer perceptions of service quality. Journal of Retailing, 1(64), 12-40. Acesso em 14 de fevereiro de 2015 
Pereira, R. G., \& de Paula, A. H. (2007). Perfil Profissional de Instrutores de Musculação das Academias da Cidade de João Monlevade-MG. Movimentum - Revista Digital de Educação Física, 2(1), pp. 1-10.

Pereira Filho, E., Campos, D. F., \& Dantas, M. L. (2013). Mensuração da Qualidade de Serviço em Academias de Ginástica: das Escalas Padronizadas ao Desenvolvimento de Uma Escala Específica. Holos, 5, pp. 175-190. Acesso em 05 de fevereiro de 2015

Pestana, M. H., \& Gageiro, J. N. (2014). Análise de Dados para Ciências Sociais: A Complementaridade do SPSS (6a. ed.). Lisboa, Lisboa, Portugal: Sílabo.

Pinheiro, I. A., \& Pinheiro, R. R. (2006). Organização Científica do Trabalho Reinventa um Mercado Tradicional: O Caso do Fitness. RAEeletrônica, 5(2), pp. 1-26. Acesso em 6 de julho de 2014

Proni, M. W. (2010). Universidade, Profissão Educação Física e o Mercado de Trabalho. Motriz: Revista de Educação Física, 16(3), pp. 788-798. Acesso em 12 de junho de 2017, disponível em http://www.scielo.br/pdf/motriz/v16n3/a27v16n3.pdf

Quaresma, L. F. (2008). GOLFE E QUALIDADE DE : Modelo Conceptual de Avaliação da Qualidade de Serviços de Golfe em Portugal. Tese de Doutoramento. Vila Real, Portugal: UTAD. Acesso em 28 de janeiro de 2015

Rego, A., Cunha, M. P., Gomes, J. F., Cunha, R. C., Cardoso-Cabral, C., \& Marques, C. A. (2015). Manual de Gestão de Pessoas e do Capital Humano ( $3^{a}$ ed.). Lisboa: Edições Sílabo.

Saba, F. K. (2001). Aderência à pratica de exercícios físicos em academias (1 ed., Vol. 1). São Paulo, SP, Brasil: Manole.

Saba, F. K. (2006). Liderança e Gestão: para Academias e Clubes Esportivos (1 ed.). São Paulo, São Paulo, Brasil: Phorte. Acesso em 2015

Sayers, P. (2012). Quality Assurance. Managing Sport and Leisure Facilities: a guide to a competitive tendering. London: Taylor \& Francis Group. Acesso em 28 de março de 2016, disponível em https://books.google.com.br/books?id=IxzWSqeomh
$\mathrm{EC} \&$ printsec $=$ frontcover $\& \mathrm{hl}=\mathrm{pt}-$

$\mathrm{BR} \&$ source $=$ gbs_ge_summary_r\&cad $=0 \# \mathrm{v}=$ onepage $\& \mathrm{q} \& \mathrm{f}=$ false.

Silvestro, R., Fitzgerald, L., Johnston, R., \& Voss, C. (1992). Towards a Classification of Service Processes. International Journal of Service Industry Management, pp. 62-75. Acesso em 25 de março de 2017, disponível em http://www.emeraldinsight.com/doi/pdfplus/10.1108/ 09564239210015175

SmartFit. (2017). Unidades SmartFit. RJ, RJ, Brasil. Acesso em 05 de agosto de 2017, disponível em http://www.smartfit.com.br/locations/?lat=$22.9068467 \& \operatorname{lng}=-43.17289649999998$

Streiner, D. L. (2003) Sendo Inconsistente Sobre Consistência: Quando Coeficiente Alfa Não Importa, Journal of Personality Assessment, 80: 3, 217-222, DOI: 10.1207 / S15327752JPA8003 01

Taveira, A., James, C., Karsh, B., \& Sainfort, F. (2003). Quality Management and the Work Environment: an Empirical Investigation in a Public Sector Organization. Applied Ergonomics, 34, pp. 281-291. Acesso em 12 de maio de 2016, disponível em

https://pdfs.semanticscholar.org/1d99/cbbb86631b1f 073a2ea8968f7c9f438bb844.pdf

Thomas, J. R., Nelson, J. K., \& Silverman, S. J. (2009). Metodos de Pesquisa em Atividade Física (6a. ed.). Porto Alegre, RS, Brasil: Artmed.

Tibola, J. A., Silva, A., Vieira, V. A., \& Tontini, G. (2011). Análise do Contraste da Penalidade e da Recompensa (PRC): Identificando atributos de qualidade em serviços de academias. Revista Eletrônica de Ciência Administrativa (RECADM), 10, pp. 140-152. doi:105329

Triado, X. M., Aparicio, P., \& Rimbau, E. (1999). Identification of factors of customers' satisfaction in municipal sport centres in Barcelona: some suggestions for satisfaction improvement. Cyber Journal of Sport Marketing, 3. Acesso em 12 de fevereiro de 2015

Tuckman, B. W. (2012). Manual de Investigação em Educação: Metodologia para cCnceber e Realizar o Processo de Investigação Científica (4a. ed.). Portugal: Fundação Calouste Gulbenkian. 
Vieira, A. A., \& Carneiro Jr., M. A. (2010). O Perfil do Profissional de Academias de Atividades Físicas da Microrregião de Ubá, MG. EFDeportes Revista Digital, 148(15).

Yildiz, S. M. (2011). An importance-performance analysis of fitness center service quality: empirical results from fitness centers in Turkey. African Journal of Business Management, 5(16), pp. 7031-7041.

Yoshida, M. (2017). Consumer experience quality: A review and extension of the sport management literature. Sport Management. 20(5). pp. 427-442. acesso em 03 de janeiro de 2019, disponível em https://www.sciencedirect.com/science/article/pii/S1 441352317300153.

Zeithaml, V. A., Bitner, M. J., \& Gremler, D. D. (2011). Marketing de Serviços: A Empresa com Foco no Cliente (5a. ed.). Porto Alegre: Bookman.

Zequinão, M. A., \& Cardoso, F. L. (2013). Criação e Avaliação das Qualidades Psicométricas do Questionário de Satisfação de Clientes em Serviços de Educação Física (QSCSEF). Revista Brasileira de Ciências do Esporte, p. 481501. Acesso em 15 de abril de 2016 